\title{
Comparison of Small Modular Reactor and Large Nuclear Reactor Fuel Cost
}

\author{
Christopher P. Pannier ${ }^{*}$, Radek Skoda ${ }^{1,2}$ \\ ${ }^{1}$ Department of Nuclear Engineering, Texas A\&M University, College Station, USA \\ ${ }^{2}$ Czech Technical University, Prague, Czech Republic \\ Email: ${ }^{*}$ cpannier@tamu.edu
}

Received 12 January 2014; revised 12 February 2014; accepted 20 February 2014

Copyright (C) 2014 by authors and Scientific Research Publishing Inc.

This work is licensed under the Creative Commons Attribution International License (CC BY). http://creativecommons.org/licenses/by/4.0/

(c) (i) Open Access

\begin{abstract}
Small modular reactors (SMRs) offer simple, standardized, and safe modular designs for new nuclear reactor construction. They are factory built, requiring smaller initial capital investment and facilitating shorter construction times. SMRs also promise competitive economy when compared with the current reactor fleet. Construction cost of a majority of the projects, which are mostly in their design stages, is not publicly available, but variable costs can be determined from fuel enrichment, average burn-up, and plant thermal efficiency, which are public parameters for many near-term SMR projects. The fuel cost of electricity generation for selected SMRs and large reactors is simulated, including calculation of optimal tails assay in the uranium enrichment process. The results are compared between one another and with current generation large reactor designs providing a rough comparison of the long-term economics of a new nuclear reactor project. SMRs are predicted to have higher fuel costs than large reactors. Particularly, integral pressurized water reactors (iPWRs) are shown to have from $15 \%$ to $\mathbf{7 0 \%}$ higher fuel costs than large light water reactors using 2014 nuclear fuels market data. Fuel cost sensitivities to reactor design parameters are presented.
\end{abstract}

\section{Keywords}

Nuclear Energy, New Nuclear, Nuclear Fuel Cost, Small Modular Reactors, SMR, Light Water Reactors

\section{Introduction}

There are over 60 electricity-generating nuclear reactors under construction around the world as of March 2013

*Corresponding author. 
[1]. Of these, only six units are considered small reactors with power ratings below 400 MWe (megawattselectric): two 30 MWe units in Russia, two 100 MWe units in China and two 320 MWe units in Pakistan [2]. In the Americas, Asia, and Europe, reactor vendors have adopted a philosophy of small modular reactor designs to reduce the capital cost and increase the number of suitable sites for new nuclear electric generation projects. These small designs are offered in addition to conventional large reactor designs to suit a variety of utility needs. The two classes of nuclear reactors (small modular and large) are expected to have different overnight, financing, and variable costs.

The development of small electric-generating nuclear reactors was strongly influenced by naval applications. These naval reactors and scaled-down versions of existing large nuclear power plants have inspired current SMR designs which can be broadly classified as integral pressurized water reactors (iPWRs), marine-derivative PWRs, boiling water reactors (BWRs), pressurized heavy water reactors (PHWRs), gas-cooled, liquid metal-cooled, and various non-conventional designs [3]-[5]. Integral pressurized water reactors (iPWRs) integrate the steam generator and pressurizer into the core pressure vessel. SMRs can be divided into two broad groups based on their design and licensing status: those for early deployment based on a proven LWR technology, and those for longer-term deployment, based on other innovative designs. Other authors have written extensively on the potential for and variety of SMR designs [6].

Generally, SMRs offer utilities the opportunity to add nuclear generating capacity with a smaller total project cost than large LWRs. Construction cost is significant to the total cost of any nuclear power project. However, after the construction cost is amortized the fuel, operations and maintenance costs drive the cost of electric generation. In other words, construction cost drives the economics in the short and medium terms, but fuel cost is important for the long term. Economies of scale tend to favor larger plants over small plants on variable costs. While the smaller SMRs may save on construction cost compared to LWRs, their variable cost of electric generation is not openly reported. In this paper, emphasis is placed on assessing the economic viability of a few selected near-term SMR designs. Through this assessment, areas for economic improvement of SMR nuclear designs will be identified.

Since the fuel of current LWRs is very similar to the fuel of several SMRs derived from them, it is straightforward to compare fuel costs of the two concepts, giving a comparison of variable costs of the two reactor classes. These papers summarize the fuel cost issue and put it into perspective with the initial capital investment, economy of scale and overall cost of construction [7] [8]. The SMR designs that use gas, liquid metal or molten salt coolants have significantly different fuel designs from the low enriched uranium dioxide fuel used in current LWRs and PWR-derived SMR designs. Therefore only the PWR-derived SMR designs are fully suitable for direct SMR to LWR fuel cost comparison.

In this paper, five SMRs based on LWRs were chosen. All SMR reactors in the study are still in pre-build or pre-licensing stages, so the design characteristics are nominal and subject to change by their designers. The five other PWR-derived designs for near term land deployment in this study are: NuScale, mPower, SMART, the Westinghouse SMR, and HI-SMUR. The NuScale power reactor is a 45 MWe reactor based on a PWR design to be installed underground with up to six units sharing a common housing [9]. The B\&W mPower reactor was announced to be installed in modules of 125 MWe with a long operating cycle between refuelings [10]. The South Korean SMART (System-integrated Modular Advanced ReacTor) is being developed by KAERI with a thermal power of $330 \mathrm{MWt}$ to be used for both electric generation and water desalination or other process heat applications [11]. The Westinghouse Small Modular Reactor (W-SMR) builds upon the design concepts of the much larger AP1000 reactor currently under construction in China and the United States. The Westinghouse SMR was announced to be a 200 MWe integral pressurized water reactor using a derivative of AP 1000 fuel [12]. Holtec Inherently Safe Modular Underground Reactor, (HI-SMUR) was announced to be a 140 MWe reactor design does not require coolant pumps as it relies on natural convection. It does not depend on off-site power for safe shutdown and thus qualifies as inherently safe. As its name implies, the HI-SMUR is to be built underground [13]. The HI-SMUR is not considered an integral PWR because its steam generators are not integrated into the reactor vessel.

Six well-known light water reactors and one large heavy water reactor were chosen to represent currently available options on the nuclear reactor market. The VVER 1000 class represents the standard Russian pressurized water reactor offered by Atomstroyexport. It is available in several power variants. Many units were built in Russia, India, China, and other countries [14]. The AP 1000 is the Westinghouse pressurized water 
reactor currently under construction in USA and China [15]. The ABWR is the Japanese boiling water reactor offered by Toshiba and Hitachi and already operated in Japan and Taiwan [16]. The EPR is Areva pressurized water reactor under construction in Finland, France, and China [17]. The US-EPR is the variant for the US market. The US-APWR is a large pressurized water reactor designed by Mitsubishi Heavy Industries [18]. The ESBWR is a boiling water reactor designed by Hitachi and General Electric [19]. Finally, the Enhanced CANDU6 is the heavy water designed in Canada [20]. It uses uranium at natural enrichment, but requires heavy water moderator in the core.

\section{Methods}

A light water moderated reactor using uranium fuel requires fuel with a ${ }^{235} \mathrm{U}$ concentration above that of natural uranium. The economics of uranium enrichment are well known and are described in literature [21]. To calculate fuel price in a nuclear system using enriched uranium fuel, one must know the price of enriched uranium used to make the fuel. This price depends on the enrichment of the fuel, a reactor design parameter. Furthermore, three market parameters are needed to calculate the price of enriched uranium: the price of $\mathrm{U}_{3} \mathrm{O}_{8}$ from a uranium mill, the price of conversion of $\mathrm{U}_{3} \mathrm{O}_{8}$ into the gaseous $\mathrm{UF}_{6}$ for enrichment, and the price of SWU (separative work units). The number of SWUs required to enrich to a certain level is a measure of the electric energy required to perform the enrichment. All three of these costs are available from the Uranium Consulting Company's uranium price indices [22].

The cost of fabricating nuclear fuel assemblies from enriched uranium is proprietary to the nuclear fuel producer and is strongly dependent on the type of fuel assembly chosen for a reactor. Integral PWR fuel is not expected to vary in the fuel fabrication techniques used for large LWRs. In a 1994 study, fuel fabrication prices are given with a range between $\$ 200$ and $\$ 400$ per $\mathrm{kg} \mathrm{U}$, with the higher costs for fuel designed to withstand a higher burnup. In that study, a value of $\$ 275 / \mathrm{kg} U$ is assumed for fabrication cost [23]. A more recent 2010 study by EPRI uses a nominal $\$ 200 / \mathrm{kg}$ U for PWR fuel fabrication cost [24]. A constant value of $\$ 275 / \mathrm{kg} U$ will be used for fabrication cost throughout this study.

To specify the cost of mining, conversion and enrichment nuclear fuel per $\mathrm{kWh}$, a simple formula will be used. When the price of nuclear material is known, the fuel cost of electrical energy produced by unit of nuclear fuel can be evaluated as:

$$
P=\frac{U}{\eta \cdot B \cdot 240}
$$

where $P$ is fuel cost in $\$ / \mathrm{kWh}, U$ is price of enriched uranium product in $\$ / \mathrm{kg}$ of uranium, $\eta$ is plant net efficiency, and $B$ is burn-up in $\mathrm{MWd} / \mathrm{kg}$ of uranium. The factor of 240 comes from the units conversion of days into hours and $\$ / M W h$ into $\$ / k W h$. For fuel cost minimization as attempted in enrichment plants, the uranium enrichment process must be optimized.

\subsection{Uranium Enrichment Optimization}

In the first step of the optimization, the optimal depletion rate of the tailing uranium is computed according the following procedure, as shown by Benedict and Pigford in [26]. Separative capacity, SC, is defined by the following formula:

$$
S C=W\left(2 x_{W}-1\right) \ln \left(\frac{x_{W}}{1-x_{W}}\right)+P\left(2 x_{P}-1\right) \ln \left(\frac{x_{P}}{1-x_{P}}\right)-F\left(2 x_{F}-1\right) \ln \left(\frac{x_{F}}{1-x_{F}}\right)
$$

where $W$ stands for waste (tails) rate in kilograms per unit time, $P$ for product rate in kilograms per unit time, $F$ for feed rate in kilograms per unit time. The mass fraction of ${ }^{235} \mathrm{U}$ are $x_{W}$ as waste enrichment (tails assay), $x_{P}$ as product enrichment, and $x_{F}$ as feed uranium enrichment. Separative capacity represents a measure of the rate at which an enrichment cascade performs the separation and is used as a measure of isotope separation work magnitude. In the isotope separation plant, the initial cost of the separation plant is proportional to the separative capacity of the plant. The annual operating costs are proportional to the separative work done per year. Separative work, $S W$, is measure of the amount of separation achieved by a cascade producing $M_{W}$ kilograms of waste and $M_{P}$ kilograms of product from $M_{F}$ kilograms of feed, and is assigned as: 


$$
\begin{aligned}
S W= & M_{W}\left(2 x_{W}-1\right) \ln \left(\frac{x_{W}}{1-x_{W}}\right)+M_{P}\left(2 x_{P}-1\right) \ln \left(\frac{x_{P}}{1-x_{P}}\right) \\
& -M_{F}\left(2 x_{F}-1\right) \ln \left(\frac{x_{F}}{1-x_{F}}\right)
\end{aligned}
$$

The annual charges for enrichment plant investment plus annual operating costs exclusive of feed is $S C \cdot c_{S}$ in $\$$ /year, where $S C$ is the annual separative capacity in kilograms of uranium per year, and $c_{S}$ is the unit cost of separative work in dollars per kilogram of separative work units (\$/kg-SWU). If $M_{F} \mathrm{~kg}$ of feed is charged per year at a unit cost of $c_{F} \$ / \mathrm{kg}$, the total annual cost $c$ is:

$$
c=S C \cdot c_{S}+M_{F} \cdot C_{F}
$$

If $P$ kg of product is made per year, the unit cost of product, $C_{p}$, is:

$$
c_{p}=\frac{S C \cdot c_{S}}{M_{F}}+\frac{M_{F} \cdot c_{F}}{M_{P}}
$$

Applying the conservation of mass equation,

$$
M_{F}=M_{P}+M_{W},
$$

and the conservation of the ${ }^{235} \mathrm{U}$ mass equation,

$$
M_{F} \cdot x_{F}=M_{P} \cdot x_{P}+M_{W} \cdot x_{W},
$$

to the enrichment plant gives two mass ratios as functions of the three mass fractions in Equations (8) and (9).

$$
\begin{aligned}
& \frac{M_{F}}{M_{P}}=\frac{x_{P}-x_{W}}{x_{F}-x_{W}} \\
& \frac{M_{W}}{M_{P}}=\frac{x_{P}-x_{F}}{x_{F}-x_{W}}
\end{aligned}
$$

The amount of separative work required in the up-stream enriching section is independent of tails composition. But the cost of separative work required in the stripping down-stream section varies from zero when $x_{W}=x_{F}$ to infinity when $x_{W}=$ Conversely, the cost of feed varies from infinity when $x_{W}=x_{F}$ to a minimum at $x_{W}$ $=0$. There is therefore an optimum tails assay, $x_{W, \text { optimal }} \in\left(0, x_{F}\right)$, at which the sum of the cost of separative work and the cost of natural uranium feed is a minimum. Optimum tails composition occurs when:

$$
\begin{gathered}
\left(\frac{\partial c_{p}}{\partial x_{W}}\right)_{x_{P}, x_{F}}= \\
c_{p}=c_{F} \frac{x_{P}-x_{W}}{x_{F}-x_{W}}+c_{S} \frac{x_{P}-x_{F}}{x_{F}-x_{W}}\left(2 x_{W}-1\right) \ln \left(\frac{x_{W}}{1-x_{W}}\right) \\
+c_{S}\left(2 x_{P}-1\right) \ln \left(\frac{x_{P}}{1-x_{P}}\right)-c_{S} \frac{x_{P}-x_{W}}{x_{F}-x_{W}}\left(2 x_{F}-1\right) \ln \left(\frac{x_{F}}{1-x_{F}}\right) \\
\frac{c_{F}}{c_{S}}=\left(2 x_{P}-1\right) \ln \left(\frac{x_{F} \cdot x_{W, \text { optimal }}}{x_{W, \text { optimal }}\left(1-x_{F}\right)}\right)+\frac{\left(x_{F}-x_{W, \text { optimal }}\right)\left(1-2 x_{W, \text { optimal }}\right)}{x_{W, \text { optimal }}\left(1-x_{W, \text { optimal }}\right)}
\end{gathered}
$$

\subsection{Fuels Market Price Inputs}

The enriched uranium cost for the selected power plants, the prices of material, conversion, and enrichment are shown in Table 1. Price input parameters are volatile and their evolution over time is shown in Figure 1 and Figure 2.

For a comparison with operating commercial nuclear power plants, performances and parameters of the selected LWRs and SMRs are shown in Table 2. 


\section{Ux U308 Price}

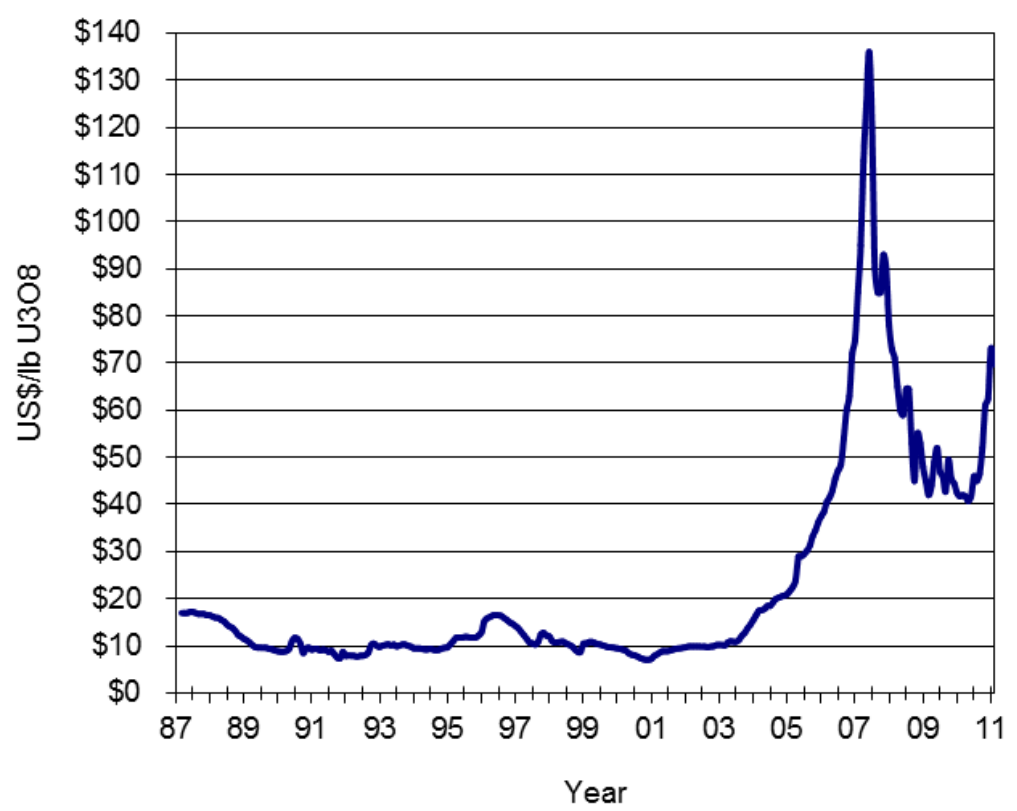

Figure 1. Price of uranium, data from UxC [22].

\section{Ux SWU Price}

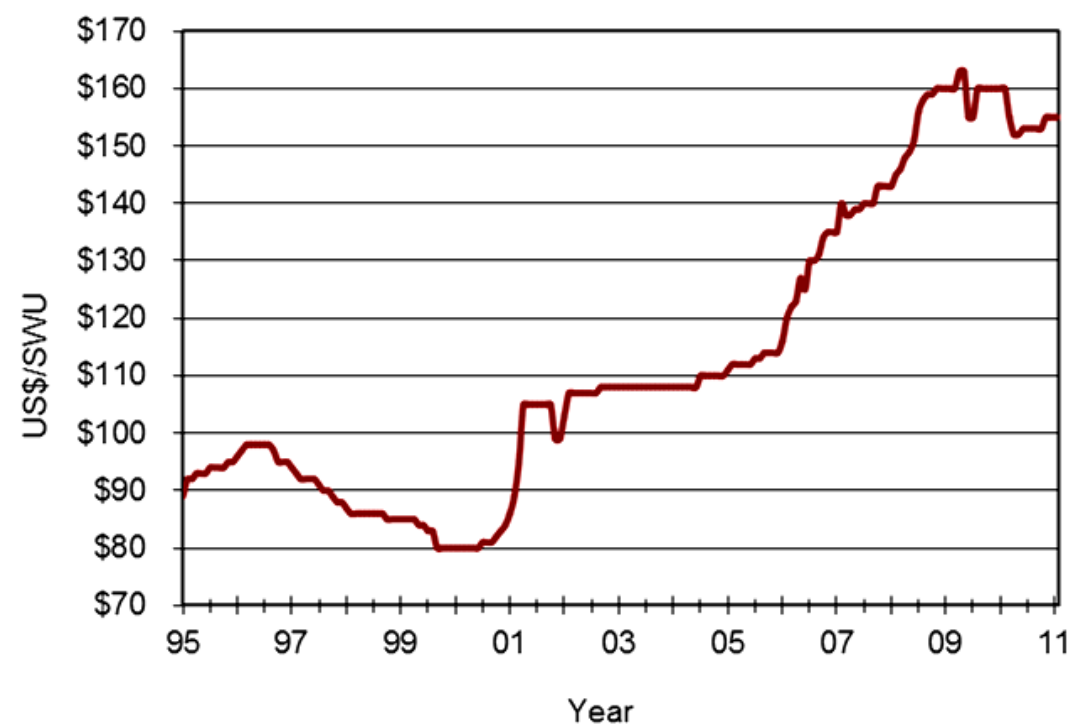

Figure 2. Price of SWU for the enrichment process, data from UxC [22].

Table 1. Mean fuels cycle cost parameters in Spring 2014.

\begin{tabular}{ccc}
\hline Parameter & Unit & Average Cost \\
\hline $\mathrm{U}_{3} \mathrm{O}_{8}$ & $\$ / \mathrm{lb}$ of $\mathrm{U}_{3} \mathrm{O}_{8}$ & 35.6 \\
Conversion & $\$ / \mathrm{kg} \mathrm{U}$ in $\mathrm{UF}_{6}$ & 8 \\
SWU & $\$ / \mathrm{SWU}$ & 98 \\
Fabrication & $\$ / k g$ U in $\mathrm{UO}_{2}$ & 275 \\
\hline
\end{tabular}


Table 2. Model inputs for selected nuclear power plant designs.

\begin{tabular}{|c|c|c|c|c|c|}
\hline Reactor design & $\begin{array}{l}\text { Average fuel } \\
\text { enrichment }\end{array}$ & $\begin{array}{l}\text { Fuel burnup } \\
{[\mathrm{GWd} / \mathrm{tU}]}\end{array}$ & $\begin{array}{c}\text { Net electric } \\
\text { power [MWe] }\end{array}$ & $\begin{array}{l}\text { Thermal power } \\
\text { output [MWt] }\end{array}$ & Plant net efficiency \\
\hline \multicolumn{6}{|l|}{ SMR } \\
\hline NuScale & $4.95 \%$ & 50 & 45 & 160 & $28 \%$ \\
\hline SMART & $4.88 \%$ & 60 & 90 & 330 & $27 \%$ \\
\hline mPower & $5.00 \%$ & 40 & 125 & 400 & $31 \%$ \\
\hline HI-SMUR & $4.95 \%$ & 35 & 140 & 450 & $31 \%$ \\
\hline W-SMR & $4.95 \%$ & 54 & 200 & 600 & $33 \%$ \\
\hline \multicolumn{6}{|l|}{ Large Reactors } \\
\hline EC 6 & Natural & 7.5 & 745 & 2084 & $36 \%$ \\
\hline VVER1000 & $3.50 \%$ & 43.4 & 1000 & 3000 & $33 \%$ \\
\hline AP1000 & $4.55 \%$ & 60 & 1100 & 3400 & $32 \%$ \\
\hline ABWR & $3.70 \%$ & 45 & 1315 & 3811 & $35 \%$ \\
\hline US-APWR & $5.00 \%$ & 62 & 1600 & 4451 & $36 \%$ \\
\hline US-EPR & $5.00 \%$ & 60 & 1600 & 4500 & $36 \%$ \\
\hline ESBWR & $4.20 \%$ & 50 & 1561.5 & 4500 & $35 \%$ \\
\hline
\end{tabular}

\section{Results}

Based on historical enrichment, conversion and uranium costs, a simulation for a given time horizon was performed using correlated simulated input variables. The calculation for all reactors resulted in full distribution of fuel cost and sensitivities to increased burn-ups. The simulated fuel cost for new large LWRs is 3.86 \$/MWh. The simulated iPWR (excludes HI-SMUR) design average fuel costs are between 3.95 and 7.47 \$MWh with an average for the iPWR reactor class of $5.84 \$$ MWh as shown in Table 3 . Hence an increase between $+15 \%$ to $+70 \%$ can be expected for iPWR SMR fuel cost compared to new large LWR fuel cost.

The simulated mean and standard deviation fuel cost for every reactor studied is presented in Table 4. The reactor types are ordered from lowest mean fuel cost to highest. The large light water reactors had the lowest mean fuel cost per unit electric energy produced. In the simulation, the large heavy water moderated reactor had a $42 \%$ higher mean fuel cost than large light water reactors. However, it must be remembered that the fabrication cost that includes the processes of cladding, assembling, and shipping new fuel elements was estimated at $\$ 275 / \mathrm{kg} U$ regardless of the fuel design. The fabrication cost for CANDU fuel may be somewhat different than the fabrication cost for LWR fuel. As shown in Figure 10 and Figure 11, heavy water reactor fuel cost is more dependent on fabrication cost than light water reactor fuel, as is to be expected for a natural enrichment fuel.

Assuming the economies of scale of large reactors (reduced neutron leakage and thermal energy losses) one would expect lower fuel cost for larger SMR units. The results do not follow this trend. Rather, SMR designers often aim for fuel management goals like long times between refueling outages or using reactor heat to desalinate seawater, both of which raise the fuel cost of electricity produced for one design over another. Current fuel management goals for SMRs are not related to reactor electric power rating in the 45 to $300 \mathrm{MW}$ electric power rating range. This may change as SMR designs mature and utilities build and operate SMRs.

Sensitivity analysis directly shows which parameters influence the fuel cost. Hence a sensitivity analysis of mean fuel cost to burnup was performed; the results are shown in Figure 3. From industry history, one can expect that plant owners will try to improve fuel economy by pushing burn-ups higher [26] through core materials modifications after a reactor is built and operating.

Plant net efficiency is not only design dependent but also strongly site dependent, so the sensitivity was calculated and the results are shown in Figure 4. Similarly, deducing from improvements in thermodynamic 
Table 3. Mean fuel cost and standard deviation for the compared reactor classes.

\begin{tabular}{cc}
\hline Reactor Class & Mean Fuel Cost [US\$/MWh] \\
\hline Large LWR & 3.86 \\
Large Reactor & 4.09 \\
PWR-Derived SMR & 5.84 \\
\hline
\end{tabular}

Table 4. Mean fuel cost and standard deviation for the compared reactor designs in order of increasing mean fuel cost.

\begin{tabular}{cccc}
\hline Reactor Type & Reactor Classes & Mean Fuel Cost [US\$/MWh] & Standard Deviation [US\$/MWh] \\
\hline US-APWR & Large LWR, Large Reactor & 3.67 & 0.116 \\
AP1000 & Large LWR, Large Reactor & 383 & 0.120 \\
US-EPR & Large LWR, Large Reactor & 3.84 & 0.121 \\
ABWR & Large LWR, Large Reactor & 3.89 & 0.120 \\
VVER1000 & Large LWR, Large Reactor & 3.95 & 0.121 \\
ESBWR & Large LWR, Large Reactor & 3.95 & 0.124 \\
W-SMR & iPWR, PWR-derived, SMR & 4.51 & 0.142 \\
SMART & iPWR, PWR-derived, SMR & 4.88 & 0.154 \\
EC-6 & Large Reactor & 5.49 & 0.091 \\
NuScale & iPWR, PWR-derived, SMR & 5.76 & 0.182 \\
mPower & iPWR, PWR-derived, SMR & 6.60 & 0.208 \\
HI-SMUR & PWR-derived, SMR & 7.47 & 0.236 \\
\hline
\end{tabular}

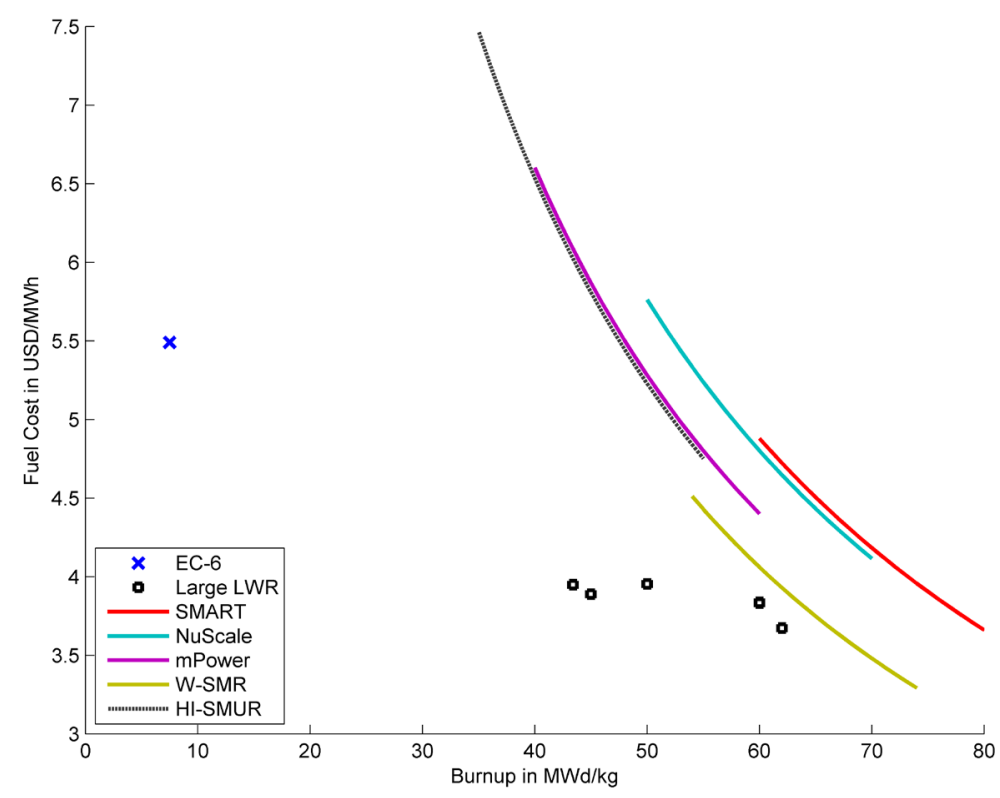

Figure 3. Fuel cost sensitivity to discharge burn-up for PWR-derived SMRs compared to large reactors.

efficiency over the last 40 years, one assumes fuel economy will be improved by better net efficiency during plant operations and in newer plant builds. The curves in Figure 4 can also be used to estimate the fuel cost for a 
site-specific net thermodynamic efficiency.

Higher fuel enrichment on its own, as illustrated on Figure 5, has a negative impact of fuel economy. However, as higher fuel enrichment goes hand in hand with a higher burn-up (other fuel limits permitting), the enrichment dependency must be presented along with the burn-up dependency for a complete picture.

Histograms of model simulation outputs are presented for the heavy water reactor, a large light water reactor and two integral pressurized water reactor SMRs in Figures 6-9.

Pie charts of the simulated average cost of each component of fuel cost are given for the heavy water reactor, a large light water reactor and two integral pressurized water reactor SMRs in Figures 10-13. Because the heavy water reactor (Enhanced CANDU 6) uses natural uranium enrichment, it has no separation or enrichment cost.

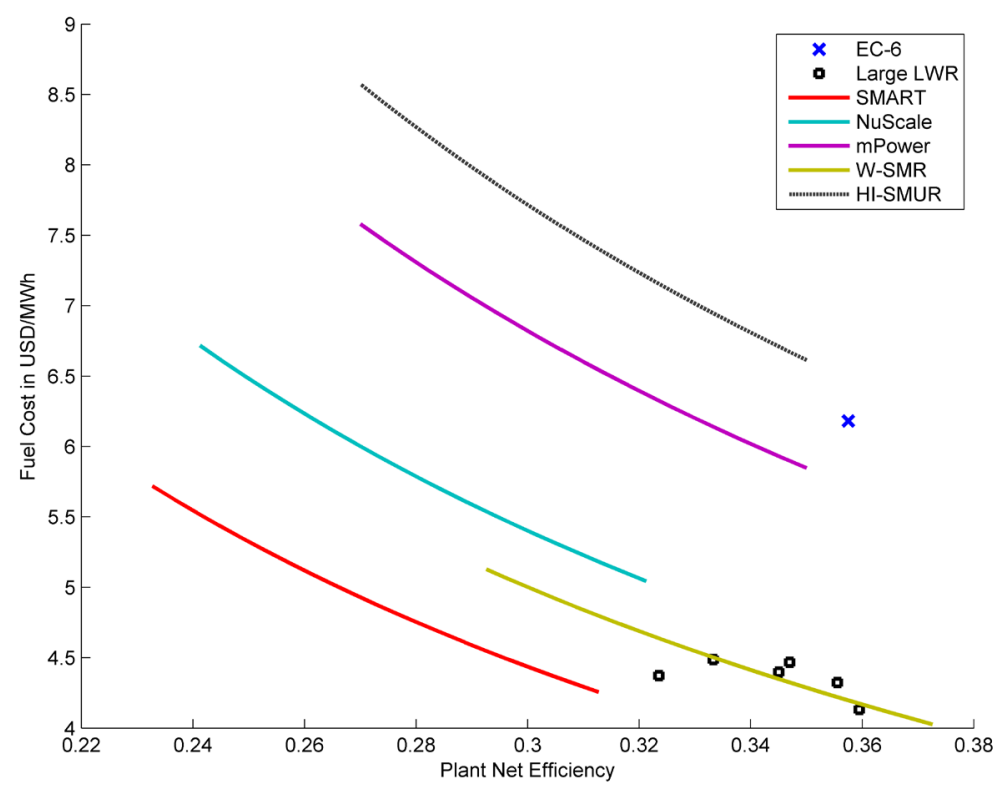

Figure 4. Fuel cost sensitivity to plant net efficiency for PWR-derived SMRs compared to large reactors.

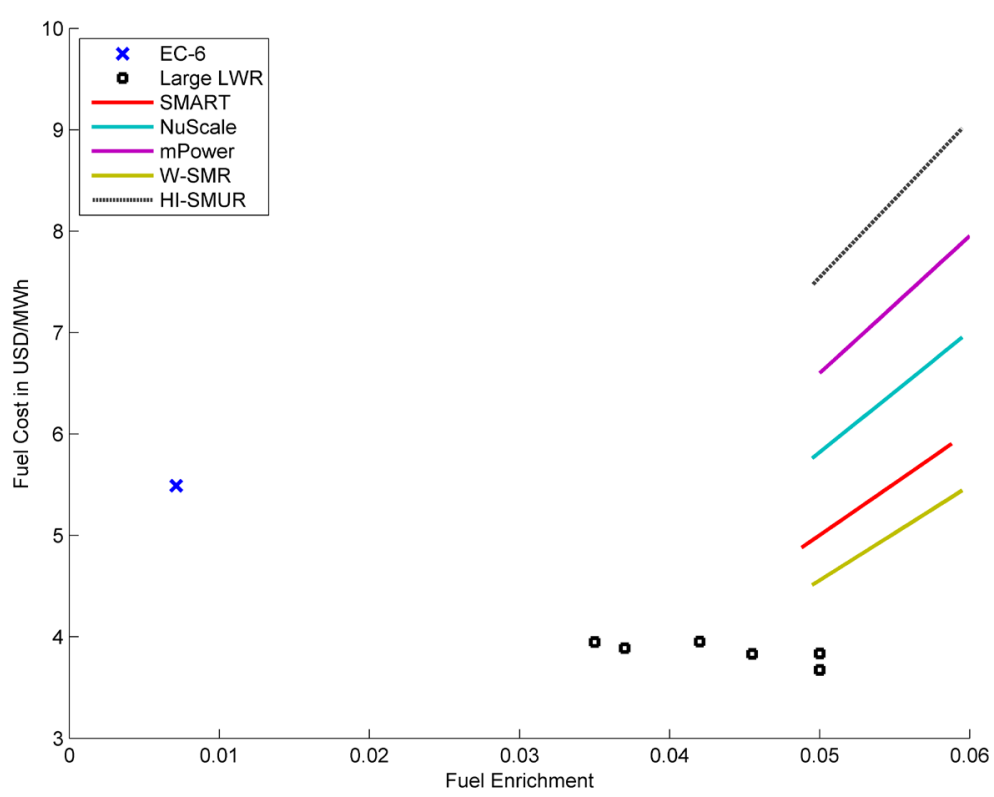

Figure 5. Fuel cost sensitivity to average fuel enrichment for PWR-derived SMRs compared to large reactors. 


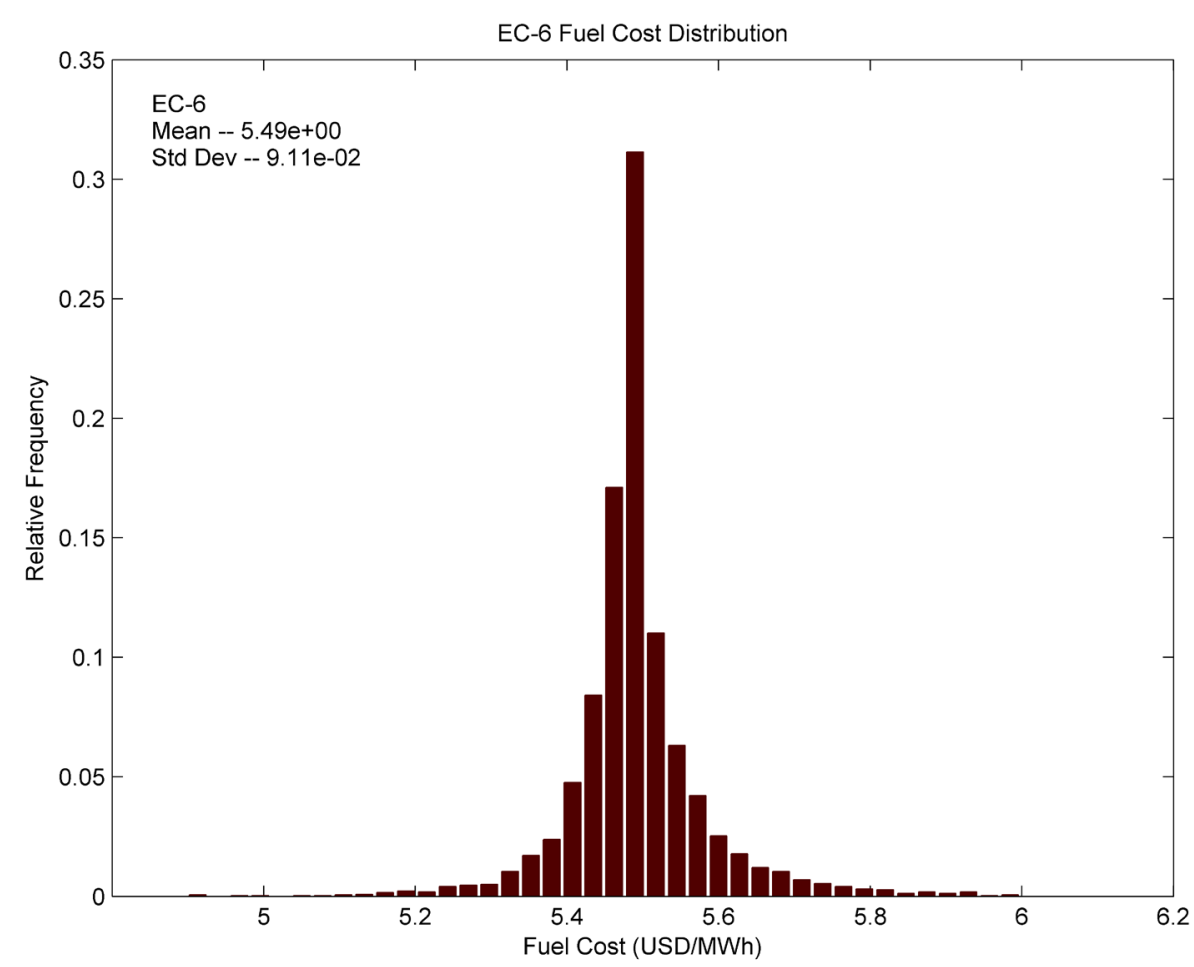

Figure 6. Fuel cost distribution for enhanced CANDU-6.

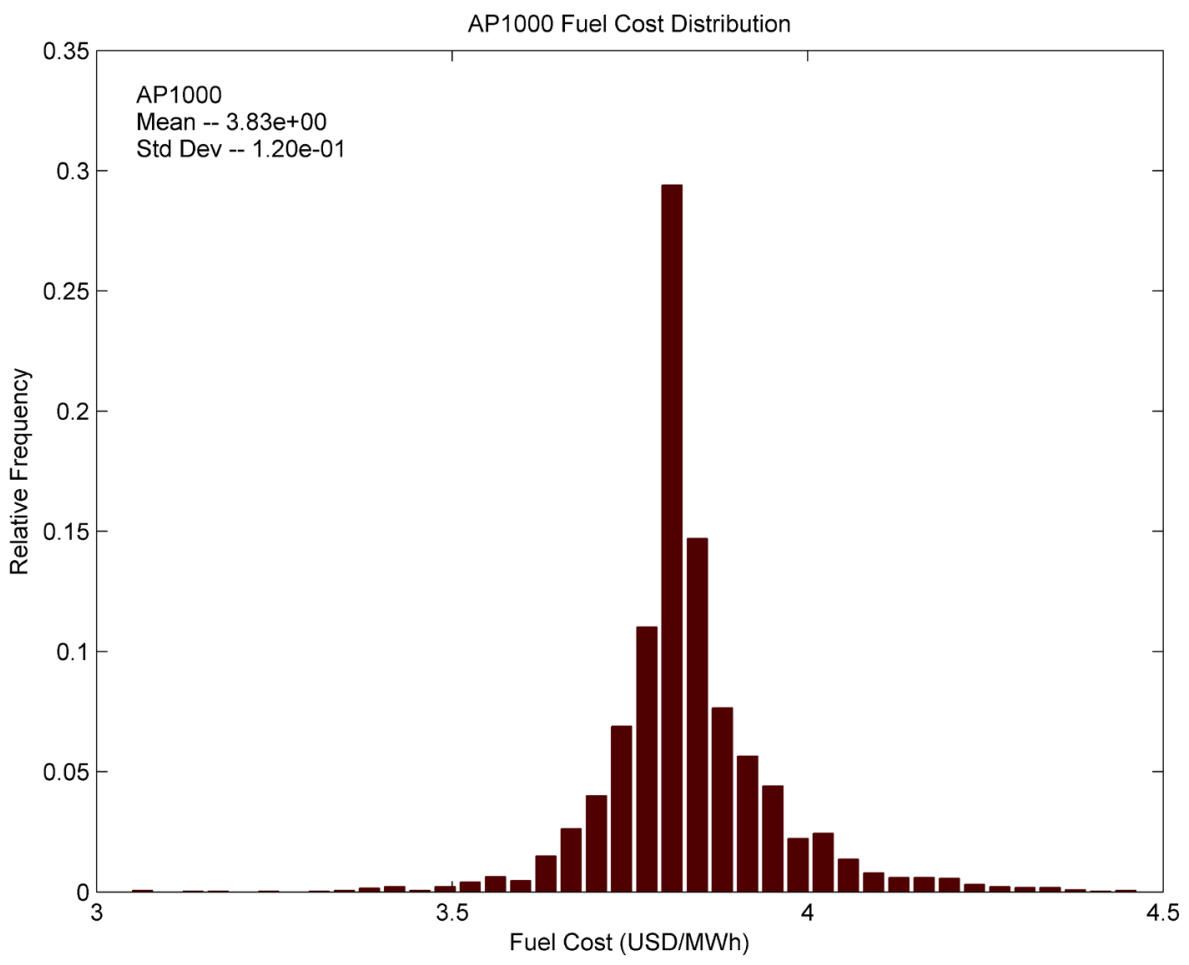

Figure 7. Fuel cost distribution for AP1000.

\section{Conclusions}

It is expected that SMRs may be easier to license and find more acceptable by the general public then current 


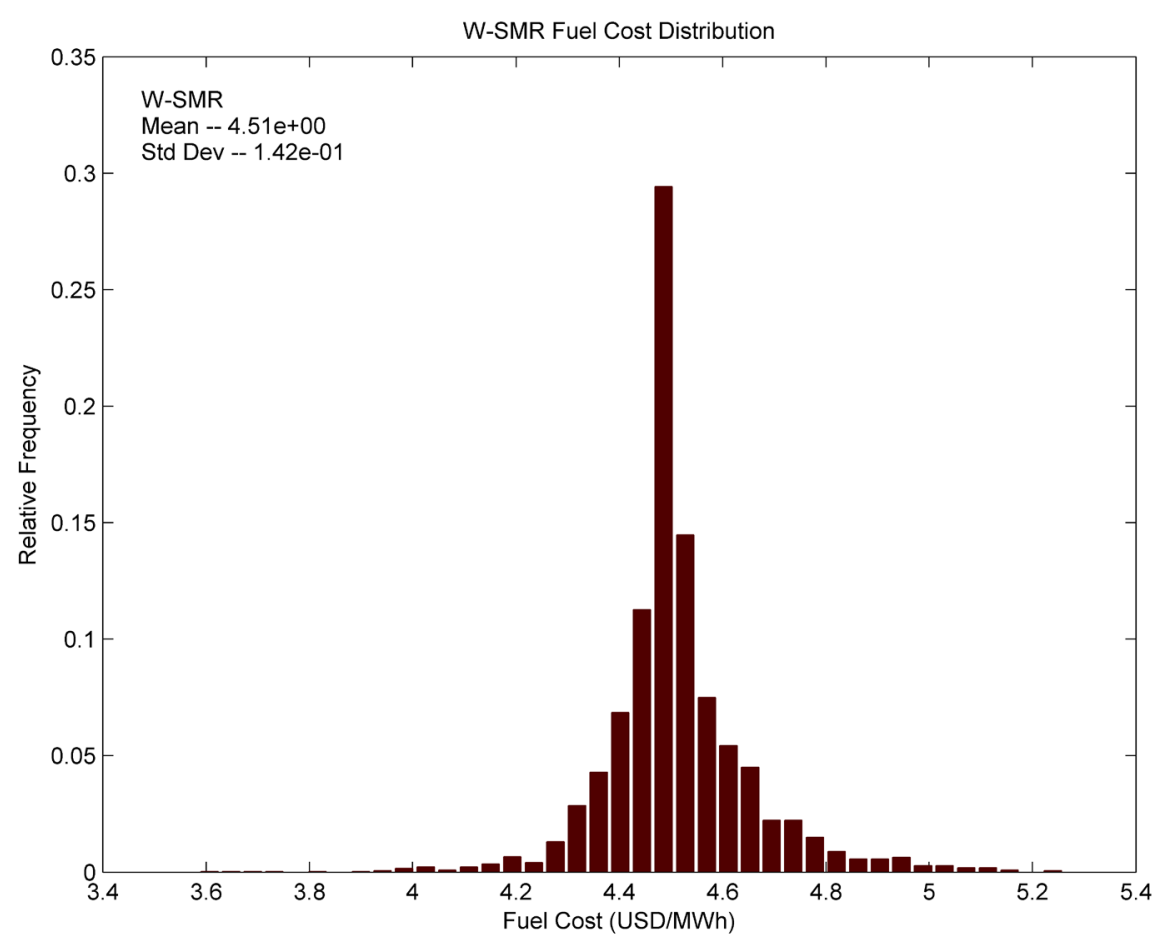

Figure 8. Fuel cost distribution for Westinghouse SMR.

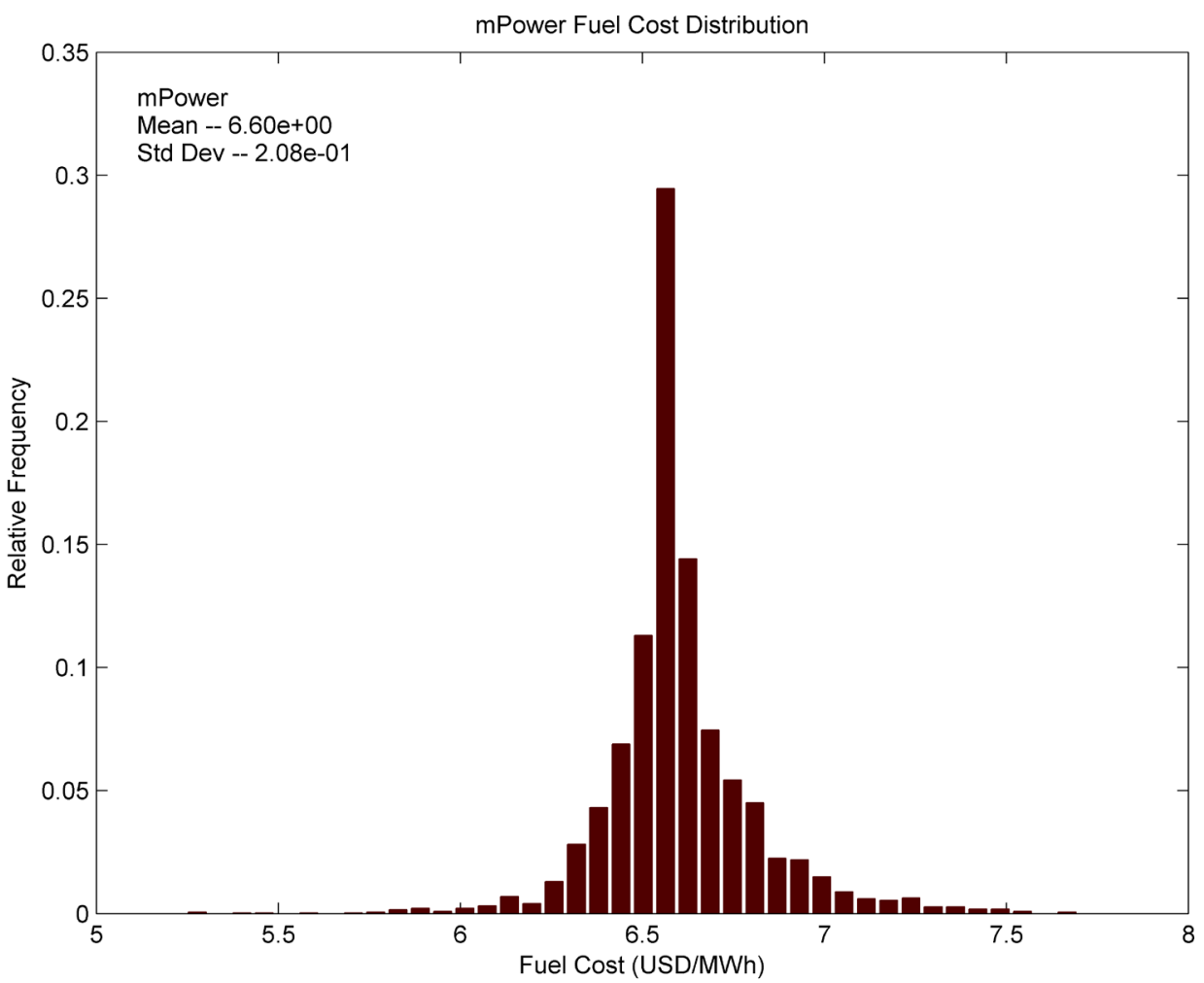

Figure 9. Fuel cost distribution for mPower.

LWRs. However, the predicted fuel cost is $15 \%$ - 70\% higher for integral pressurized water reactor type small and modular reactors than for currently operating or under-construction large reactors. Other studies indicate 
EC-6 Fuel Cost Components

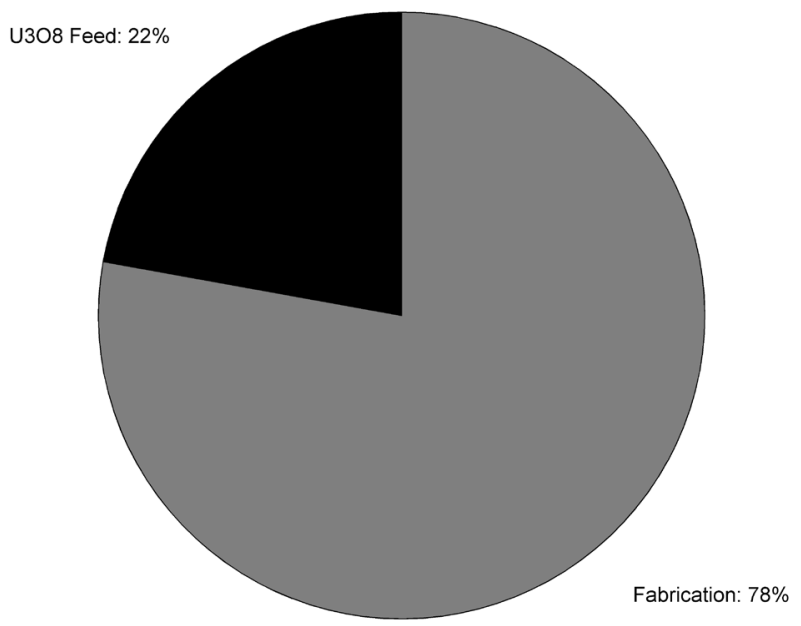

Figure 10. Fuel cost components for enhanced CANDU-6.

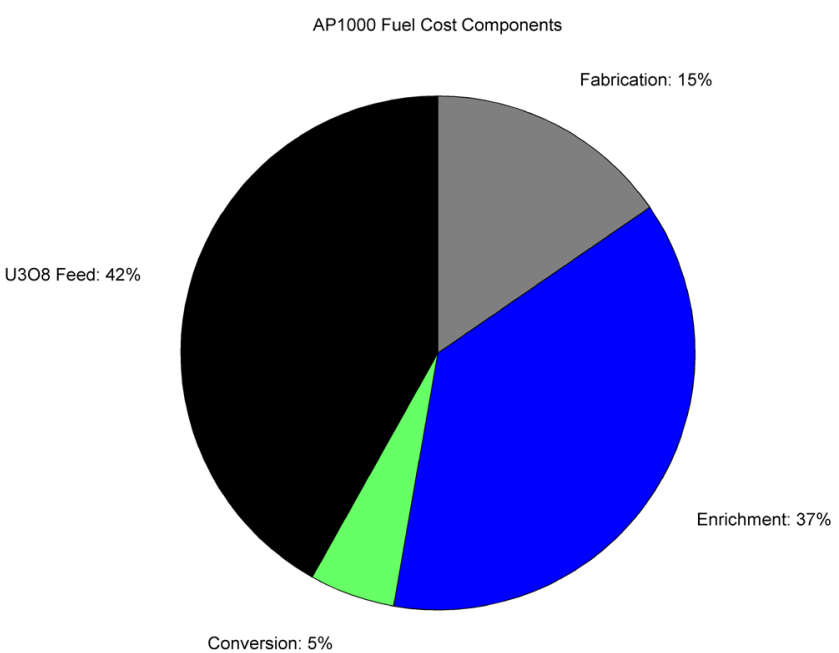

Figure 11. Fuel cost components for AP1000.

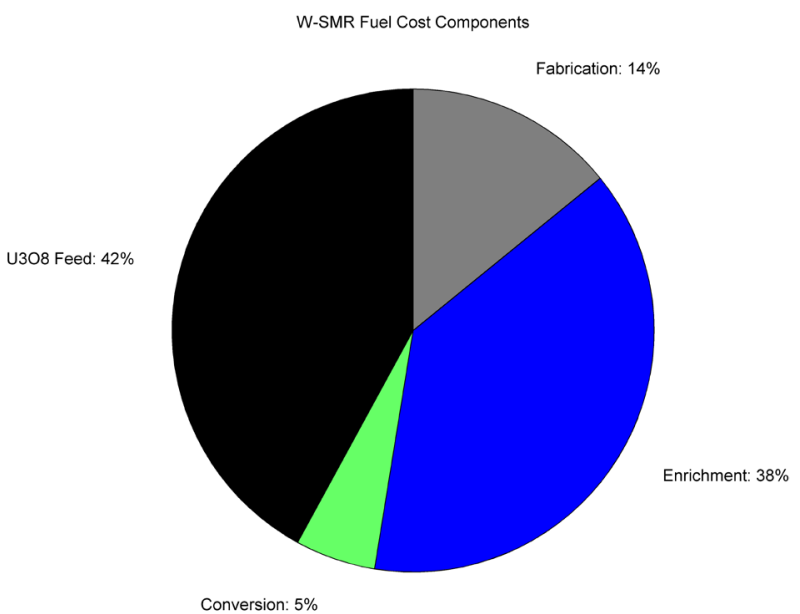

Figure 12. Fuel cost components for Westinghouse SMR. 


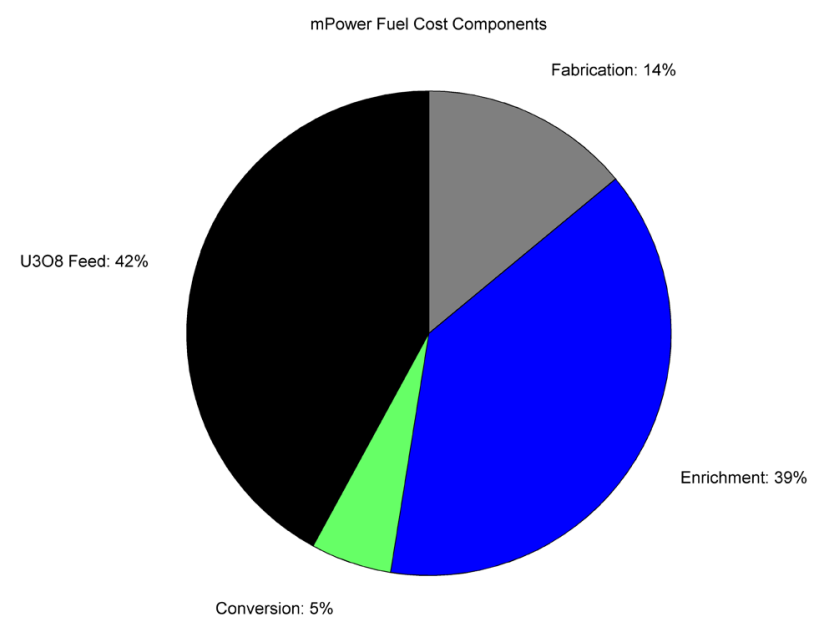

Figure 13. Fuel cost components for mPower.

that the fixed construction cost of small and large nuclear power stations have a similar behavior [7]. In conclusion, the projected range of the fuel cost when producing electricity from SMRs shows these reactors are more fuel-wise expensive than current large LWRs.

There are a few caveats to this analysis: The resulting averages presented above should not be used to compare one design to another as the model inputs give a snapshot of reactor design parameters in 2011 and simulated fuel market parameters in 2014. Specific designs may have experienced design changes in enrichment, burnup and thermodynamic efficiency. However, the averages are well-suited to compare one class of reactors to another. Plant thermodynamic efficiency is site-specific (ambient temperature of the cooling water source) and can thus change model inputs. Furthermore, as operating experience leads to efficiency in SMR operation, discharge burn-up and thermal efficiency are expected to rise, driving the fuel cost down. This pattern was experienced with LWRs when discharge burn-ups nearly doubled from 1970 to 2005 [26]. However, technologies that allow for increased fuel burn-up will improve the future fuel economics of both large and small reactors.

\section{Acknowledgements}

The authors would like to acknowledge Texas A\&M University, Department of Nuclear Engineering and the Nuclear Power Institute for providing funding to present the results. Special thanks to Eric Webb of UxC for providing historic uranium, conversion and SWU price data. Anonymous reviewer comments improved the paper.

\section{References}

[1] World Nuclear Association (2013) Plans for New Reactors Worldwide. http://world-nuclear.org/info/Current-and-Future-Generation/Plans-For-New-Reactors-Worldwide/

[2] World Nuclear Association (2013) Small Nuclear Power Reactors. http://www.world-nuclear.org/info/Nuclear-Fuel-Cycle/Power-Reactors/Small-Nuclear-Power-Reactors/

[3] Ingersoll, D. (2009) Deliberately Small Reactors and the Second Nuclear Era. Presentation at UC Berkeley.

[4] Greenspan, E. and Brown, N. (2001) Small Innovative Reactor Designs-Useful Attributes and Status of Technology. Rise University, Houston.

[5] Michal, R. (2004) Interview with Argonne’s David Wade: On the Development of Small Modular Reactors. https://smr.inl.gov/Document.ashx?path=DOCS\%2fReading+Room\%2fArgonneDavidWade2004-8-2.pdf

[6] Vujić, J., Bergman, R., Škoda, R. and Miletić, M. (2011) Small Modular Reactors: Simpler, Safer, Cheaper? Proceedings of ECOS 2011, Novi Sad, 4-7 July 2011, 2842-2852.

[7] Locatelli, G. (2010) SMR Economics Evaluation. Proceedings of the 4th Annual Asia-Pacific Nuclear Energy Forum on Small and Medium Reactors (SMRs): Benefits and Challenges, Berkeley, 17-19 June 2010.

[8] Pannier, C. and Skoda, R. (2011) Assessment of Small Modular Reactor Fuel Cost. Proceedings of ASME 2011 Small 
Modular Reactors Symposium, Washington DC, 28-30 September 2011.

[9] Landrey, B. (2010) Introduction to NuScale Power. Proceedings of the 4th Annual Asia-Pacific Nuclear Energy Forum on Small and Medium Reactors (SMRs): Benefits and Challenges, Berkeley, 17-19 June 2010.

[10] Babcock \& Wilcox (2010) B\&W mPower Reactor Design Overview. http://pbadupws.nrc.gov/docs/ML1015/ML101550512.pdf

[11] Lee, W. (2010) The SMART Reactor. Proceedings of the 4th Annual Asia-Pacific Nuclear Energy Forum on Small and Medium Reactors (SMRs): Benefits and Challenges, Berkeley, 17-19 June 2010.

[12] Fetterman, R., Harkness, A., Smith, M. and Taylor, C. (2011) An Overview of the Westinghouse Small Modular Reactor. Proceedings of ASME 2011 Small Modular Reactors Symposium. ASME, Washington DC, 28-30 September 2011.

[13] Singh, K., Rampall, I. and Rajkumar, J. (2011) On the Thermal-Hydraulic Essentials of the Holtec Inherently Safe Modular Underground Reactor (HI-SMUR) System. Proceedings of ASME 2011 Small Modular Reactors Symposium. ASME, Washington DC, 28-30 September 2011.

[14] Elemash (2004) VVER-1000 Nuclear Fuel. http://www.elemash.ru/en/production/Products/NFCP/VVER1000/

[15] Westinghouse (2003) Westinghouse AP 1000 Advanced Nuclear Plant: Plant Description. http://www.ne.doe.gov/pdfFiles/AP1000 Plant Description.pdf

[16] Tepco (2010) Sustainability Report 2010. http://www.tepco.co.jp/en/challenge/environ/pdf-1/10report-e.pdf

[17] Areva (2007) UK EPR, Fundamental Safety Overview, Vol. 1: Head Document, Chapter A: EPR Design Description. http://www.if.uidaho.edu/gunner/ME443-543/HW/UK-EPR.pdf

[18] Suzuki, S., Ogata, Y., Nishihara, Y. and Fujita, S. (2008) Global Development of Mitsubishi Standard APWR as an Effective Countermeasure Against Global Warming. Mitsubishi Heavy Industries, Ltd., Technical Review, 45, 51-54. http://www.mhi.co.jp/technology/review/pdf/e453/e453051.pdf

[19] GE Hitachi Nuclear Energy (2010) ESBWR Design Control Document Tier 2. http://pbadupws.nrc.gov/docs/ML1034/ML103440210.pdf

[20] CANDU Energy Inc. (2012) Enhanced CANDU 6 Technical Summary. Mississauga. http://www.candu.com/site/media/Parent/EC6\%20Technical\%20Summary 2012-04.pdf

[21] Cochran, R. and Tsoulfanidis, N. (1999) The Nuclear Fuel Cycle: Analysis and Management. 2nd Edition, American Nuclear Society, La Grange Park.

[22] The Ux Consulting Company (2011) UxC Prices. http://uxc.com/review/uxc Prices.aspx

[23] Nuclear Energy Agency (1994) The Economics of the Nuclear Fuel Cycle. OECD, Paris. http://www.oecd-nea.org/ndd/reports/efc/

[24] Electric Power Research Institute (2010) Parametric Study of Front-End Nuclear Fuel Cycle Costs Using Reprocessed Uranium. EPRI Report 1020659. http://cybercemetery.unt.edu/archive/brc/20120621082115/http://brc.gov/sites/default/files/documents/1020659.pdf

[25] Benedict, M. andPigford, T. (1957) Nuclear Chemical Engineering. McGraw-Hill, New York.

[26] International Atomic Energy Agency (2007) Current Trends in Nuclear Fuel for Power Reactors. Proceedings of IAEA 2007 General Conference. http://www.iaea.org/About/Policy/GC/GC51/GC51InfDocuments/English/gc51inf-3-att5_en.pdf 